\title{
Competição de Plantas daninhas com a Cultura do Café em DuAs ÉPOCAS DE INFESTAÇÃO ${ }^{1}$
}

\author{
Competition of Weeds with Coffee Plants, in Two Times of Infestation
}

FIALHO, C.M.T. ${ }^{2}$, SILVA, G.R. ${ }^{3}$, FREITAS, M.A.M. ${ }^{4}$, FRANÇA, A.C. ${ }^{5}$, MELO, C.A.D. ${ }^{6}$ e SILVA, A.A. ${ }^{7}$

\begin{abstract}
RESUMO - Objetivou-se com este trabalho avaliar a interferência de plantas daninhas instaladas aos 60 e aos 180 dias após o transplantio de plantas de café em vasos contendo $25 \mathrm{dm}^{3}$ de substrato. O experimento foi instalado no delineamento em blocos casualizados, com quatro repetições, em esquema fatorial ( $2 \times 4 \times 2)$, com duas espécies de plantas daninhas (Brachiaria decumbens e Brachiaria plantaginea), cultivadas por 90 dias, em quatro densidades (zero, dois, quatro e seis plantas por vaso), juntamente com mudas de café de diferentes idades: 60 e 180 dias após transplantio. Na colheita do experimento foram avaliados o incremento na altura, na área foliar e no diâmetro do coleto do café, a matéria seca de plantas daninhas e do café e a densidade radicular do café. Estimaram-se, ainda, a razão de massa foliar, a razão de massa caulinar, a razão de massa radicular, a razão de área foliar e a razão sistema radicular/parte aérea das plantas de café. As plantas daninhas proporcionaram interferência negativa nas características avaliadas. Verificou-se menor incremento em altura, área foliar e matéria seca total das plantas de café com o aumento da densidade das plantas daninhas. O efeito da interferência das plantas daninhas foi maior quando a interferência se instalou aos 60 dias após o transplantio. Nesse caso, houve menor acúmulo das variáveis de crescimento, porém as duas gramineas comportaram-se de forma similar, não diferindo para a maioria das variáveis. As plantas de café foram mais sensiveis à competição com $B$. plantaginea em relação a $B$. decumbens quando a competição se instalou aos 180 dias após o transplantio. O aumento da densidade de plantas daninhas promoveu maior alocação de fotoassimilados para a parte aérea em detrimento do sistema radicular do café.
\end{abstract}

Palavras-chave: Braquiaria decumbens, Braquiaria plantaginea, Coffea arabica, interferência, manejo integrado.

\begin{abstract}
The aimed of this work was to evaluate the weed interference installed at 60 and 180 days after coffee seedlings transplanted in pots contend $25 \mathrm{dm}^{3}$ of substrate. The experiment was arranged in a randomized blocs, with four replications, in factorial design ( $2 \times 4 \times 2)$, with two weed species (Brachiaria decumbens and Brachiaria plantaginea), cultured per 90 days, in four densities (zero, two, four and six plants per pot), together with coffee seedlings of different ages: 60 and 180 days after transplanted. In the moment of the experiment harvest was evaluated the increment in plant height, in leaf area and in girth diameter of the coffee, dry matter of weeds and coffee, and coffee root density. It also estimated the leaf mass ratio, stem mass ratio, root mass ratio, root system/shoot ratio of coffee plants. The weeds provided negative interference in the characteristics evaluated. Verified was smaller increase of height, leaf area and total dry matter of coffee plants with the increase of weed density. The effects of plants interference were bigger when the interference was installed sooner. In this case smaller occurred accumulation of growth variables; however both grasses behaved of similar way not differing for the most variables. When the competition was installed later the coffee plants were more sensible to competition the B. plantaginea in relation to $B$. decumbens. The increase of weed densities promoted bigger allocation of photoassimilates for the shoot part in detriment to coffee root system.
\end{abstract}

Keywords: Brachiaria decumbens, Brachiaria plantaginea, Coffea arábica, interference, integrated management.

1 Recebido para publicação em 5.9.2010 e na forma revisada em 17.12.2010.

2 Engâ-Agr ${ }^{\mathrm{a}}$., M.Sc., Doutoranda, Dep. de Fitotecnia, Universidade Federal de Viçosa - DFT/UFV, 36570-000 Viçosa-MG, <cintiamtfialho@yahoo.com.br>; ${ }^{3}$ Estudante de Agronomia, UFV, <gustavorodriguessilva@gmail.com>; ${ }^{4}$ Eng $^{-}-$Agr ${ }^{0}$., Mestrando, DFT/UFV, <marcofreitas11@yahoo.com.br>; ${ }^{5}$ Engo-Agr ${ }^{\circ}$., D.Sc., Professor, Universidade Federal dos Vales do Jequitinhonha e Mucuri - UFVJM, Faculdade de Ciências Agrárias, Campus II, Rodovia MGT 367, Km 583, no 5.000 Bairro Alto da Jacuba, 39100-000 Diamantina-MG, <cabralfranca@yahoo.com.br>; ${ }^{4}$ Eng ${ }^{\mathrm{a}}-\mathrm{Agr}{ }^{\mathrm{a}}$., Mestrando, DFT/UFV, <marcofreitas11@yahoo.com.br>; ${ }^{6}$ Engo-Agrō. $^{-}$D.Sc., Professor Associado, DFT/UFV, <aasilva@ufv.br>.

Planta Daninha, Viçosa-MG, v. 28, p. 969-978, 2010. Número Especial 


\section{INTRODUÇÃO}

Dentre as culturas com grande importância econômica e social do Brasil, destaca-se a do café arábica. Apesar do Brasil ser o maior produtor mundial de café, a produtividade dessa cultura é baixa, considerando o seu potencial. As principais causas dessa baixa produtividade são: o fato de muitas lavouras serem antigas e depauperadas, deficiências nutricionais, bienalidade de produção, estresse abiótico e biótico e manejo inadequado da cultura (Caixeta et al., 2008). Entre esses fatores listados, destaca-se a interferência das plantas daninhas com a cultura do café jovem. Essas possuem elevada capacidade competitiva pelos recursos do meio: água, nutrientes e luz; e se não manejadas corretamente afetam negativamente o crescimento vegetativo do cafeeiro (Ronchi et al., 2006) e posteriormente sua produtividade.

Segundo Silva et al. (2008), a competição das plantas daninhas com o café é mais severa durante a formação da lavoura (primeiro e segundo ano após a implantação) e também nos meses de outubro a março (época das águas), periodo que coincide com a frutificação do cafeeiro. A presença das plantas daninhas em lavouras de café é influenciada pelas chuvas e pelas temperaturas mais elevadas. Nessas condições, ocorre grande infestação da área por gramíneas e diversas dicotiledôneas que se não controladas a tempo podem prejudicar a lavoura.

O cafeeiro apresenta crescimento lento em relação ao das plantas daninhas, permitindo que elas exerçam maior competição pelos recursos disponiveis que a cultura. A interferência imposta por essas plantas resulta na diminuição do teor de nutrientes nas folhas (Ronchi et al., 2003), menor crescimento (Ronchi et al., 2006), e, consequentemente, menor produção do cafeeiro. A presença de outras espécies na entrelinha do café pode trazer beneficios para a cultura, como o aumento da diversidade biótica e o aumento da proteção da superficie do solo contra o processo de erosão e imobilização de grandes quantidades de nutrientes.

Deste modo, estudos sobre o comportamento, biologia e mecanismos de interferência entre plantas daninhas e cultura do café são de extrema importância para se garantir a sustentabilidade das lavouras. Neste traba1ho, objetivou-se avaliar a interferência de Brachiaria plantaginea e Brachiaria decumbens sobre o crescimento de plantas de café com infestações ocorrendo aos 60 e 180 dias após o transplantio das mudas visando otimizar o sistema de manejo integrado de plantas daninhas em lavoura de café arábica.

\section{MATERIAL E MÉTODOS}

O experimento foi conduzido em casa de vegetação no Departamento de Fitotecnia, em Viçosa, Minas Gerais. Mudas de café Mundo Novo (linhagem 374/19), no estádio de cinco pares de folhas completamente expandida, produzidas de modo tradicional, foram plantadas em vasos contendo $25 \mathrm{dm}^{3}$ de substrato. Como substrato, utilizou-se terra de subsolo peneirada e esterco de curral curtido (3:1). Para fornecimento de $\mathrm{P}_{2} \mathrm{O}_{5}$, utilizou-se de superfosfato simples (100 g por vaso), além de calcário dolomítico, a fim de elevar a saturação de bases para $60 \%$, segundo a analise de solo (Tabela 1). Após o plantio das mudas, os vasos permaneceram sob sistema de irrigação por aspersão, até o plantio das plantas daninhas. Adicionaram-se $\mathrm{K}_{2} \mathrm{O}(31,48 \mathrm{~g}$ por vaso $)$ e $\mathrm{N}$ (10 g por vaso) aos vasos, sendo parcelados aos 30 e 60 e 120 dias após o transplantio.

O experimento foi instalado no delineamento em blocos casualizados, com quatro repetições, em esquema fatorial ( $2 \times 4 \times 2)$, com duas espécies de plantas daninhas (B. decumbens e B. plantaginea), em quatro densidades (zero, duas, quatro e seis plantas, por vaso), juntamente com mudas de café de diferentes idades: 60 e 180 dias após transplantio (DAT). A parcela experimental foi constituída de um vaso, contendo uma planta de café.

Utilizou-se bandejas de plástico contendo substrato de areia lavada para germinação das sementes das plantas daninhas, que foram posteriormente transplantadas para os vasos. As plantas daninhas foram transplantadas em mesma época, para isso, o café foi plantado em épocas distintas com intervalo de 120 dias. O periodo de convivência das plantas de café com as plantas daninhas foi aquele compreendido do transplantio até o florescimento das 
Tabela 1 - Características físicas e químicas do Latossolo Vermelho-Amarelo utilizado no experimento ${ }^{1^{\prime}}$

\begin{tabular}{|c|c|c|c|c|c|c|c|c|c|c|c|}
\hline \multicolumn{12}{|c|}{ Análise granulométrica $\left(\mathrm{dag} \mathrm{kg}^{-1}\right)$} \\
\hline \multicolumn{3}{|c|}{ Areia } & \multicolumn{3}{|c|}{\begin{tabular}{l|l} 
Silte & \\
\end{tabular}} & \multicolumn{3}{|c|}{ Argila } & \multicolumn{3}{|c|}{ Classe textural } \\
\hline \multicolumn{2}{|c|}{46} & & \multicolumn{2}{|c|}{5} & & \multicolumn{2}{|c|}{49} & & \multicolumn{3}{|c|}{ Argilo-arenosa } \\
\hline \multicolumn{12}{|c|}{ Análise química } \\
\hline $\mathrm{pH}$ & $\mathrm{P}$ & $\mathrm{K}$ & $\mathrm{Ca}^{2^{+}}$ & $\mathrm{Mg}^{2^{+}}$ & $\mathrm{Al}^{+}$ & $\mathrm{H}+\mathrm{Al}$ & SB & $\mathrm{T}$ & $\mathrm{T}$ & $\mathrm{m}$ & $\mathrm{V}$ \\
\hline$\left(\mathrm{H}_{2} \mathrm{O}\right)$ & \multicolumn{2}{|c|}{$\left(\mathrm{mg} \mathrm{dm}^{-3}\right)$} & \multicolumn{7}{|c|}{$\left(\mathrm{cmol}_{\mathrm{c}} \mathrm{dm}^{-3}\right)$} & \multicolumn{2}{|c|}{$(\%)$} \\
\hline 4,7 & 2,3 & 48 & 1,4 & 0,4 & 0,6 & 6,27 & 1,92 & 2,52 & 8,19 & 24 & 23 \\
\hline P-rem & \multicolumn{2}{|c|}{$\mathrm{Zn}$} & $\mathrm{Fe}$ & \multicolumn{2}{|c|}{$\mathrm{Mn}$} & \multicolumn{2}{|l|}{$\mathrm{Cu}$} & $\mathrm{B}$ & \multicolumn{3}{|c|}{$\mathrm{MO}$} \\
\hline$\left(\mathrm{mg} \mathrm{L}^{-1}\right)$ & \multicolumn{8}{|c|}{$\left(\mathrm{cmol}_{\mathrm{c}} \mathrm{dm}^{-3}\right)$} & \multicolumn{3}{|c|}{$\left(\right.$ dag kg $\left.^{-1}\right)$} \\
\hline 24,3 & \multicolumn{2}{|c|}{2,6} & 91,3 & \multicolumn{2}{|c|}{14,3} & \multicolumn{2}{|l|}{1,1} & 0,7 & \multicolumn{3}{|c|}{2,4} \\
\hline
\end{tabular}

1/ Análises realizadas no Laboratório de Análises Físicas e Químicas de Solo do Departamento de Solos da Universidade Federal de Viçosa

espécies de plantas daninhas (aproximadamente 90 dias).

No transplantio das plantas daninhas para os vasos e no encerramento do experimento, determinaram-se a altura e a área foliar por método não destrutivo (Antunes et al., 2008) do café. No final do experimento, as plantas de café foram seccionadas rente ao solo, sendo separadas em parte aérea e sistema radicular. A densidade do sistema radicular foi determinada pela razão entre matéria fresca e volume de água deslocado $\left(\mathrm{g} \mathrm{mL}^{-1}\right)$. Do mesmo modo, as plantas daninhas foram separadas em parte área e sistema radicular. As plantas de café e plantas daninhas foram colocadas em estufa de circulação forçada de ar $\left(65^{\circ} \mathrm{C}\right)$, até atingir massa constante, para determinação da matéria seca. Em seguida, estimaram-se: razão de massa foliar (matéria seca foliar/matéria seca total, $\mathrm{g} \mathrm{g}^{1}$ ), razão de massa caulinar (matéria seca caulinar/matéria seca total, $\mathrm{g} \mathrm{g}^{-1}$ ), razão de massa radicular (matéria seca radicular/matéria seca total $\mathrm{g} \mathrm{g}^{-1}$ ), razão de área foliar (área foliar/matéria seca total, $\mathrm{m}^{2} \mathrm{~g}^{-1}$ ) e razão do sistema radicular/parte aérea (matéria seca do sistema radicular/ matéria seca parte aérea, $\mathrm{g} \mathrm{g}^{-1}$ ).

Para a interpretação dos dados, empregouse a análise de variância utilizando-se o teste $\mathrm{F}(\mathrm{p} \leq 0,05)$. Efetuou-se o desdobramento da interação significativa e empregou-se o teste Tukey a 5\% de probabilidade de erro. Para as comparações entre espécies, foi empregada a análise de regressão para as densidades das plantas daninhas, com escolha dos modelos baseada na sua significância, no fenômeno biológico e no coeficiente de determinação $\left(R^{2}=\right.$ S.Q. Reg./S.Q. Trat.).

\section{RESULTADOS E DISCUSSÃO}

Para as variáveis matéria seca da raiz do café e das plantas daninhas, observou-se efeito significativo da interação entre os fatores tempo, densidade e espécie, assim como para a interação tempo $\mathrm{x}$ espécie para as variáveis do café: incremento em altura, densidade radicular, matéria seca total, razão de massa foliar, razão de massa radicular, razão sistema radicular/parte aérea e para matéria seca das folhas de planta daninha. Para a interação tempo $\mathrm{x}$ densidade houve efeito significativo para incremento de altura, densidade radicular, matéria seca total do café. Para algumas variáveis como área foliar, razão de massa foliar, razão de massa caulinar, razão de massa radicular, razão de área foliar, razão de sistema radicular/parte aérea, houve efeito significativo para densidade de plantio.

As plantas de café cultivadas com B. plantaginea, independentemente da fase de desenvolvimento do cafeeiro (60 ou 180 DAT), apresentaram menor incremento em altura em relação às plantas de café que conviveram com $B$. decumbens (Tabela 2). Para a densidade radicular, houve diferença do efeito das plantas daninhas de acordo com a idade da planta, sendo que as plantas de café aos 180 DAT apresentaram os menores valores. A densidade 
Tabela 2 - Variáveis do café (60 e 180 dias após o transplantio) após convivência por 90 dias com a $B$. decumbens e $B$. plantaginea e matéria seca da folha de plantas daninhas $(\mathrm{MSFPD})^{1}$

\begin{tabular}{|l|l|r|r|}
\hline \multirow{2}{*}{ Variável } & \multirow{2}{*}{ Espécie } & \multicolumn{2}{|c|}{ Época } \\
\cline { 3 - 4 } & & $60 \mathrm{DAT}$ & $180 \mathrm{DAT}$ \\
\hline \multirow{2}{*}{$\mathrm{IA}^{\underline{2} /}(\mathrm{cm})$} & B. decumbens & $29,08 \mathrm{Aa}$ & $26,27 \mathrm{Ba}$ \\
\cline { 2 - 4 } & B. plantaginea & $26,21 \mathrm{Ab}$ & $23,70 \mathrm{Ab}$ \\
\hline \multirow{2}{*}{$\mathrm{DR}\left(\mathrm{g} \mathrm{mL}^{-1}\right)$} & B. decumbens & $0,41 \mathrm{Aa}$ & $0,22 \mathrm{Ba}$ \\
\cline { 2 - 4 } & B. plantaginea & $0,39 \mathrm{Aa}$ & $0,19 \mathrm{Bb}$ \\
\hline \multirow{2}{*}{ MST $\left(\mathrm{g}^{2}\right)$} & B. decumbens & $54,08 \mathrm{Ba}$ & $238,67 \mathrm{Aa}$ \\
\cline { 2 - 4 } & B. plantaginea & $52,47 \mathrm{Ba}$ & $229,68 \mathrm{Ab}$ \\
\hline \multirow{2}{*}{$\mathrm{RMF}\left(\mathrm{g} \mathrm{g}^{-1}\right)$} & B. decumbens & $0,39 \mathrm{Aa}$ & $0,35 \mathrm{Ba}$ \\
\cline { 2 - 4 } & B. plantaginea & $0,41 \mathrm{Aa}$ & $0,31 \mathrm{Bb}$ \\
\hline \multirow{2}{*}{$\mathrm{RMR}\left(\mathrm{g} \mathrm{g}^{-1}\right)$} & B. decumbens & $0,21 \mathrm{Aa}$ & $0,22 \mathrm{Ab}$ \\
\cline { 2 - 4 } & B. plantaginea & $0,20 \mathrm{Ba}$ & $0,26 \mathrm{Aa}$ \\
\hline \multirow{2}{*}{$\mathrm{SR} / \mathrm{PA}\left(\mathrm{g} \mathrm{g}^{-1}\right)$} & B. decumbens & $0,27 \mathrm{Aa}$ & $0,26 \mathrm{Ab}$ \\
\cline { 2 - 4 } & B. plantaginea & $0,29 \mathrm{Aa}$ & $0,35 \mathrm{Aa}$ \\
\hline \multirow{2}{*}{$\mathrm{MSFPD}(\mathrm{g})$} & B. decumbens & $30,41 \mathrm{Ab}$ & $15,70 \mathrm{Bb}$ \\
\cline { 2 - 4 } & B. plantaginea & $47,40 \mathrm{Aa}$ & $53,70 \mathrm{Aa}$ \\
\hline
\end{tabular}

${ }^{1 /}$ Medias seguidas pela mesma letra, maiúscula na linha e minúscula na coluna não diferem entre si pelo teste de Tukey $(\mathrm{P}<0,05) .{ }^{2 /}$ IA(Incremento de altura), DR- (Densidade radicular), MST- (Matéria seca total), RMF- (Razão de massa foliar), RMR- (Razão de massa radicular), SR/PA- (Razão sistema radicular/ parte aérea), DATDias após o transplantio.

radicular do café que conviveu com as plantas daninhas foi de $0,40 \mathrm{~g} \mathrm{~mL}^{-1}$, aos $60 \mathrm{DAT}$, contudo, para as plantas de café mais desenvolvidas (180 DAT) a densidade radicular foi de $0,22 \mathrm{~g} \mathrm{~mL}^{-1}$ e $0,19 \mathrm{~g} \mathrm{~mL}^{-1}$ para $B$. decumbens e B. plantaginea, respectivamente (Tabela 2).

A matéria seca total de plantas de café apresentou diferença entre as espécies de plantas daninhas com as quais competiu somente aos 180 DAT, sendo B. plantaginea a espécie que proporcionou menor acúmulo desta variável (Tabela 2). Provavelmente, isso ocorreu porque a $B$. plantaginea é mais competitiva que a $B$. decumbens quando em competição com plantas mais velhas de café, pois em plantas mais jovens não houve diferença entre as espécies. B. plantaginea apresentou maiores teores de nutrientes que a $B$. decumbens, com até três vezes mais $\mathrm{P}$ e duas vezes mais $\mathrm{Mg}$ e também maiores teores de micronutrientes como $\mathrm{Mn}$ e $\mathrm{Zn}$ (dados não mostrados). As plantas de café que passaram a conviver com as plantas daninhas aos 180 DAT apresentaram maior matéria seca final, este resultado é devido ao maior tempo de desenvolvimento das mudas não podendo ser atribuído somente ao efeito da competição das plantas daninhas. Silva et al. (2008) constataram que no sistema convencional de cultivo, $80 \%$ da matéria seca das plantas daninhas foi atribuída à $B$. plantaginea, afetando diretamente o rendimento das culturas. Esses resultados reforçam a importância do manejo dessa espécie em áreas de cafeicultura em implantação.

Para a razão de massa foliar a diferença proporcionada pelas plantas daninhas somente foi observada aos 180 DAT, quando a $B$. plantaginea apresentou maior redução dessa relação em convivio com o café. Entretanto, observou-se o contrário para a razão de massa radicular, ou seja, a $B$. plantaginea proporcionou maior razão de massa radicular em relação a $B$. decumbens para as plantas de café aos 180 DAT (Tabela 2). Assim, houve maior alocação dos fotoassimilados para a raiz e menor alocação para as folhas do café que conviveu com $B$. plantaginea, em relação ao café que conviveu com a $B$. decumbens. Houve, também, maior razão sistema radicular/parte aérea das plantas de café em convivência com a $B$. plantaginea que iniciou convivio com as plantas daninhas aos 180 DAT (Tabela 2), provavelmente devido a maior alocação de fotoassimilados para a raiz nas plantas de café em convivio com esta espécie. Essa é uma tentativa da planta em investir em determinado compartimento devido a maior carência de recurso (Poorter \& Nagel, 2000).

Com relação ao acúmulo de matéria seca de plantas daninhas, observou-se que a $B$. plantaginea acumulou maior matéria seca que a $B$. decumbens, nas duas fases de desenvolvimento do café. Todavia, o acúmulo mais evidente da $B$. plantaginea foi observado aos 180 DAT (53,70 g), comparado a 15,70 g de $B$. decumbens (Tabela 2). Esse acúmulo diferencial das espécies pode estar relacionado com as suas características intrínsecas, ou, pelo fato das plantas de café já estarem mais desenvolvidas, com maior estatura, o sombreamento causado pelo café pode ter afetado o desenvolvimento da $B$. decumbens, sendo a B. plantaginea mais competitiva mesmo com o sombreamento causado pelo café.

As plantas de café que passaram a conviver com as plantas daninhas aos 60 DAT apresentaram modelo de redução exponencial de 
incremento em altura à medida que se aumentou a densidade de plantas daninhas. Para as plantas de café que passaram a conviver com as plantas daninhas aos 180 DAT, não houve efeito significativo da densidade de plantas daninhas sobre o incremento em altura (Figura 1). As testemunhas do café mais jovem (60 DAT) apresentaram maior incremento em altura em relação as plantas mais velhas, provavelmente pela menor limitação física ao crescimento das raízes causada pelo vaso, pela idade da planta ou pela época de cultivo (Figura 1). Em trabalhos similares com plantas de café, vasos de $12 \mathrm{~L}$ podem ter superestimado a competição de plantas daninhas, pelo tamanho reduzido do vaso associado ao tempo de cultivo prolongado (Ronchi et al., 2006). Observou-se, que o efeito negativo causado pelo aumento da densidade de plantas daninhas foi mais expressivo em plantas mais jovens de café, sendo estas mais sensiveis à interferência das plantas daninhas. Ronchi et al. (2006), estudando a interferência de plantas daninhas sobre plantas de café em sua fase inicial de desenvolvimento (30 DAT), observaram que Bidens pilosa, Commelina diffusa, Leonurus sibiricus e Richardia brasiliensis causaram redução drástica no crescimento de plantas de café, principalmente com o aumento da densidade.

Observou-se redução exponencial da densidade radicular com o aumento da densidade de plantas daninhas. As plantas de café (60 DAT), livre da competição, apresentaram $0,55 \mathrm{~g} \mathrm{~mL}^{-1}$, enquanto na densidade de seis plantas por vaso a densidade radicular foi de $0,32 \mathrm{~g} \mathrm{~mL}^{-1}$ (Figura 1). Na diferença observada
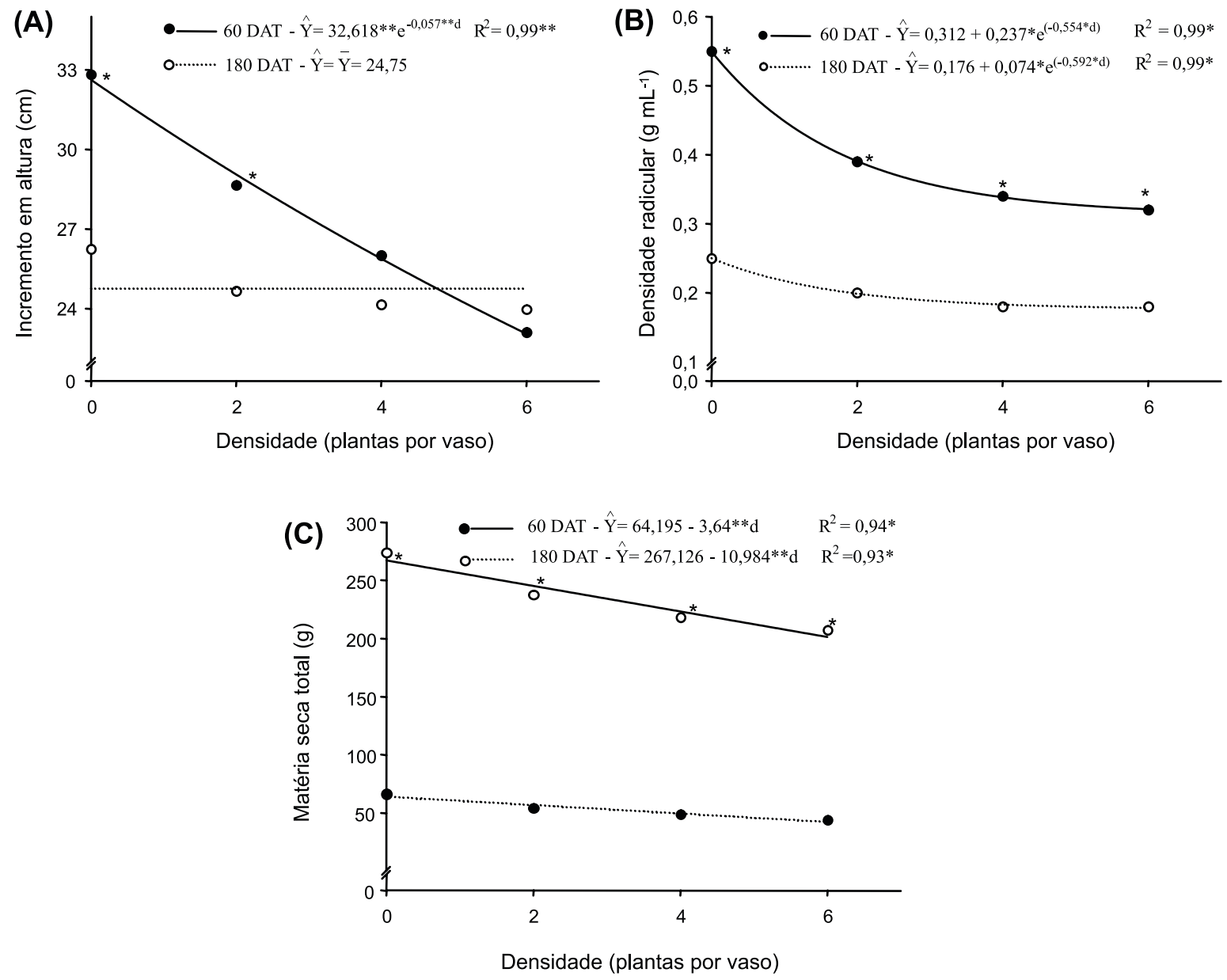

Figura 1 - Incremento em altura (A), densidade radicular (B) e matéria seca total (C) de plantas de café (60 e 180 dias após o transplantio) após convivência por 90 dias com diferentes densidades de plantas daninhas. ${ }^{*}$ Médias diferem entre si pelo teste de Tukey $(\mathrm{P}<0,05)$. 
na densidade de zero, plantas daninhas para a densidade máxima foi de $0,23 \mathrm{~g} \mathrm{~mL}^{-1}$, para duas idades do café.

Independentemente da idade do cafeeiro, houve redução linear da matéria seca, e no total das plantas com o aumento da densidade das plantas daninhas, observou-se que, para as plantas aos 60 DAT, houve redução de 22,49 g $(33,8 \%)$ entre a testemunha e a máxima densidade de plantas daninhas. Para as plantas que passaram a conviver em fase mais avançado (180 DAT) com as plantas daninhas, esta redução foi de 66,1 g (24,35 \%) (Figura 1). Proporcionalmente ao tamanho das plantas de café, houve maior redução da matéria seca total para as plantas que passaram a conviver com as plantas daninhas aos 60 DAT. Marcolini et al. (2009), verificaram que a $B$. decumbens, quando se desenvolveu perto das plantas de café, proporcionou efeito negativo pronunciado com o aumento da densidade das plantas daninhas, enquanto aos 10 e $20 \mathrm{~cm}$ de distância, o efeito foi mais pronunciado com a densidade de 16 plantas $\mathrm{m}^{-2}$.

As variáveis: razão de área foliar e razão de massa caulinar apresentaram significância apenas para o fator idade das plantas de café. As plantas de café apresentaram maior razão de área foliar e razão de massa caulinar quando em convívio com as plantas daninhas aos 60 DAT (Tabela 3). Assim, o café que passou a conviver com as plantas daninhas em fase mais avançada de desenvolvimento (180 DAT) apresentou menor alocação de fotoassimilados para o caule e para as folhas em relação às plantas de café que tiveram o início do período de competição aos 60 DAT do café. Segundo Silva et al. (2005) houve um declínio da razão de área foliar com o crescimento de plantas de Brachiaria brizantha

Tabela 3 - Razão de área foliar (RAF) e razão de massa caulinar (RMC) das plantas de café (60 e 180 dias após o transplantio) em convivência com a B. decumbens e B. plantaginea após 90 dias $^{1 /}$

\begin{tabular}{|c|c|c|}
\hline Época & RAF $\left(\mathrm{m}^{-2} \mathrm{~g}^{-1)}\right.$ & $\operatorname{RMC}\left(\mathrm{g} \mathrm{g}^{-1}\right)$ \\
\hline 60 DAT & $2,70 \mathrm{a}$ & $1,85 \mathrm{a}$ \\
\hline $180 \mathrm{DAT}$ & $0,38 \mathrm{~b}$ & $0,42 \mathrm{~b}$ \\
\hline
\end{tabular}

1/ Médias seguidas pela mesma letra na coluna, não diferem entre si pelo teste de Tukey $(\mathrm{P}<0,05)$ independente do manejo que foi utilizado. Com o crescimento das plantas, aumenta o autosombreamento, e a tendência é de a área foliar útil diminuir e consequentemente diminuir a razão de área foliar.

As plantas de café que passaram a conviver com as plantas daninhas a partir dos 60 DAT apresentaram menor acúmulo da matéria seca de raiz para todas as densidades e para as duas espécies de plantas daninhas em comparação as plantas de café aos 180 DAT. Provavelmente, isso ocorreu porque às plantas de café aos 180 DAT desenvolveram no vaso por 120 dias a mais que as outras (60 DAT), e apresentaram maior formação de sistema radicular (Tabela 4) e, portanto, menor interferência das plantas daninhas. Para as plantas de café aos 60 DAT, não houve diferença entre as plantas daninhas para as diferentes densidades. Todavia para as plantas de café que passaram a conviver com as plantas daninhas aos 180 DAT, na densidade de duas e quatro plantas por vaso, a $B$. plantaginea proporcionou menor acúmulo de matéria seca de raízes do café (Tabela 4). Na densidade de seis plantas daninhas por vaso não houve diferença entre as espécies daninhas. Segundo McCully, 1999, as interações entre raiz-raiz e raiz-solo são muito complexas. Uma série de fatores tanto do meio de desenvolvimento como do próprio sistema radicular (fisiologia da raiz, tamanho do sistema radicular, distribuição, arquitetura, taxa de crescimento) vão influenciar no desenvolvimento e na capacidade competitiva de cada planta. Além disso, a importância desses fatores vai depender do meio de cultivo, disponibilidade de água, nutrientes, toxicidade, deficiências, estrutura do solo e doenças (Dunbadin, 2007).

As plantas daninhas que foram transplantadas no vaso aos 60 DAT do café apresentaram maior acúmulo de matéria seca da raiz em relação às plantas daninhas que foram transplantadas aos 180 DAT para todas as densidades (Tabela 5). Provavelmente, devido ao maior desenvolvimento do café aos 180 DAT, que proporcionou maior sombreamento das plantas daninhas, ou pela própria limitação física de desenvolvimento das raízes das plantas daninhas. Sendo assim, as plantas mais jovens de café são mais sensiveis à interferência das plantas daninhas. Outro fator de 
Tabela 4 - Matéria seca da raiz do café (60 e 180 dias após o transplantio) em função da densidade de B. decumbens e B. plantaginea

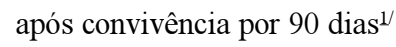

\begin{tabular}{|l|c|c|c|c|c|c|c|c|}
\hline \multirow{2}{*}{ Espécie } & \multicolumn{2}{|c|}{ Densidade 0 } & \multicolumn{2}{c|}{ Densidade 2 } & \multicolumn{2}{c|}{ Densidade 4 } & \multicolumn{2}{c|}{ Densidade 6} \\
\cline { 2 - 9 } & $60 \mathrm{DAT}$ & $180 \mathrm{DAT}$ & $60 \mathrm{DAT}$ & $180 \mathrm{DAT}$ & $60 \mathrm{DAT}$ & $180 \mathrm{DAT}$ & $60 \mathrm{DAT}$ & $180 \mathrm{DAT}$ \\
\hline B. decumbens & $17,31 \mathrm{Ba}$ & $80,71 \mathrm{Aa}$ & $11,6 \mathrm{Ba}$ & $63,4 \mathrm{Aa}$ & $9,5 \mathrm{Ba}$ & $60,6 \mathrm{Aa}$ & $8,6 \mathrm{Ba}$ & $47,2 \mathrm{Aa}$ \\
\hline B. plantaginea & $17,33 \mathrm{Ba}$ & $82,42 \mathrm{Aa}$ & $10,4 \mathrm{Ba}$ & $53,1 \mathrm{Ab}$ & $9,3 \mathrm{Ba}$ & $37,9 \mathrm{Ab}$ & $6,9 \mathrm{Ba}$ & $39,0 \mathrm{Aa}$ \\
\hline
\end{tabular}

1/ Para cada densidade, médias seguidas pela letra maiúscula na linha e letra minúscula na coluna não diferem entre si pelo teste de Tukey $(\mathrm{P}<0,05)$

Tabela 5 - Matéria seca de raiz de plantas daninhas em função da fase de desenvolvimento do café (60 e 180 dias após transplantio) e da densidade de $B$. decumbens e B. plantaginea após convivência por 90 dias $^{1 /}$

\begin{tabular}{|l|l|l|l|l|l|l|}
\hline \multirow{2}{*}{ Espécie } & \multicolumn{2}{c|}{ Densidade 2 } & \multicolumn{2}{c|}{ Densidade 4 } & \multicolumn{2}{c|}{ Densidade 6 } \\
\cline { 2 - 7 } & \multicolumn{1}{|c|}{$60 \mathrm{DAT}$} & \multicolumn{1}{|c|}{$180 \mathrm{DAT}$} & $60 \mathrm{DAT}$ & \multicolumn{1}{c|}{$180 \mathrm{DAT}$} & \multicolumn{1}{c|}{$60 \mathrm{DAT}$} & $180 \mathrm{DAT}$ \\
\hline B. decumbens & $33,2 \mathrm{Ab}$ & $12,77 \mathrm{Ba}$ & $44,09 \mathrm{Ba}$ & $24,40 \mathrm{Ba}$ & $46,24 \mathrm{Aa}$ & $17,69 \mathrm{Ba}$ \\
\hline B. plantaginea & $72,44 \mathrm{Aa}$ & $22,44 \mathrm{Ba}$ & $46,96 \mathrm{Aa}$ & $24,89 \mathrm{Ba}$ & $37,34 \mathrm{Aa}$ & $28,34 \mathrm{Aa}$ \\
\hline
\end{tabular}

${ }^{1 /}$ Para cada densidade, médias seguidas pela mesma letra maiúscula na linha e letra minúscula na coluna não diferem entre si pelo teste de Tukey $(\mathrm{P}<0,05)$.

competição entre planta daninha e a cultura do café são as raízes absorventes do cafeeiro que crescem superficialmente no solo, onde a maioria das raízes das plantas daninhas ocorre (Njoroge, 1994). Estudos revelam que o

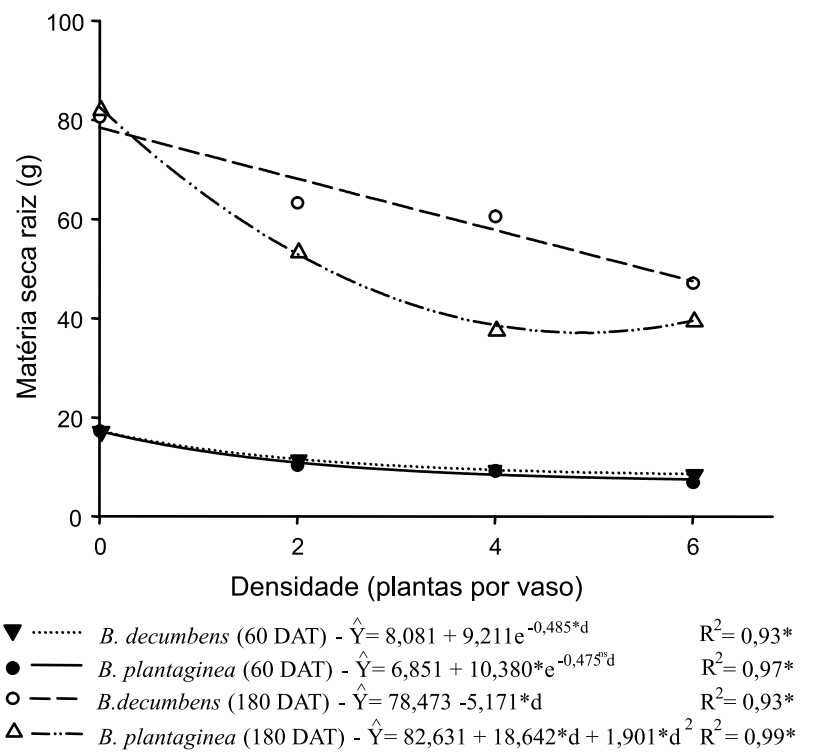

Figura 2 - Matéria seca da raiz do café (60 e 180 dias após o transplantio) em função da densidade de B. decumbens e B. plantaginea após convivência por $90 \mathrm{dias}^{1 /}$. ( ${ }^{*}$ Teste F; P $<0,05$ e nsP - Não significativo). que confere a capacidade competitiva as plantas daninhas é a capacidade de ocuparem o volume do solo e a alta taxa de crescimento, característica que a maioria destas espécies possui, aumentando a interferência durante o estabelecimento da cultura (Craine, 2006).

Houve redução quadrática do incremento de área foliar do café à medida que se aumentou a densidade de plantas daninhas (Figura 3). Para as plantas de café que desenvolveram na ausência de plantas daninhas, o incremento de área foliar foi de $3.226,10 \mathrm{~cm}^{2}$, enquanto que para as plantas de café que conviveram com a máxima densidade de plantas daninhas o incremento chegou a apenas $2.613,98 \mathrm{~cm}^{2}$, portanto redução de $19 \%$ (Figura 3). Segundo Marcolini et al. (2009), em trabalhos avaliando a interferência da densidade de $B$. decumbens sobre plantas jovens de café, todas as características avaliadas foram afetadas negativamente pela interferência da gramínea, sendo que a área foliar e a matéria seca de folhas mostraram-se mais sensiveis à interferência.

Com o aumento da densidade de plantas daninhas houve aumento discreto e linear da razão de massa caulinar do café (Figura 4). Para cada planta daninha adicionada ao vaso, o aumento foi de $0,006 \mathrm{~g} \mathrm{~g}^{-1}$ na razão de massa 
caulinar. Também, houve aumento exponencial da razão de massa foliar do café, entretanto, ocorreu queda exponencial na razão de massa radicular com o aumento da densidade de plantas daninhas. Com o aumento do número de plantas daninhas por vaso, a planta de café aumentou a alocação de fotoassimilados para parte área, como observado com a

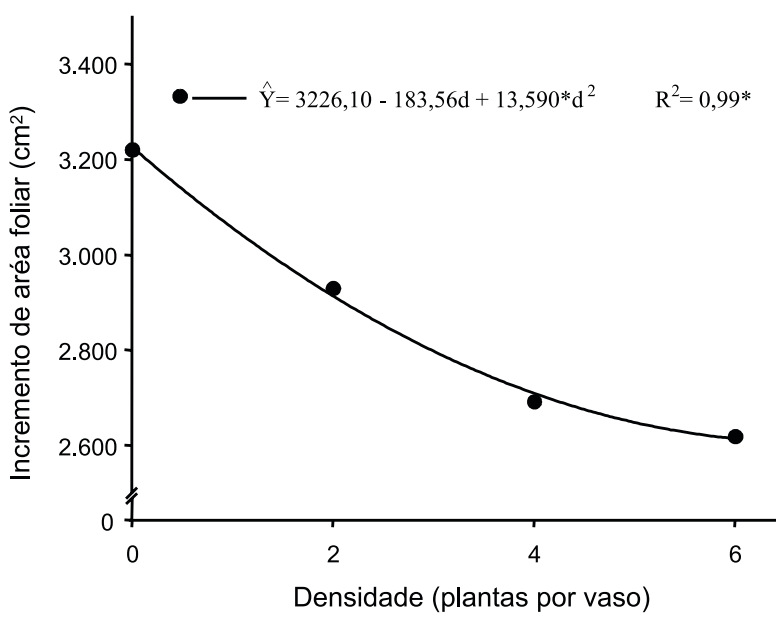

Figura 3 - Incremento de área foliar de plantas de café em função da densidade de plantas daninhas, após 90 dias de convivência. (* Teste $\mathrm{F}$; $\mathrm{P}<0,05$ ).

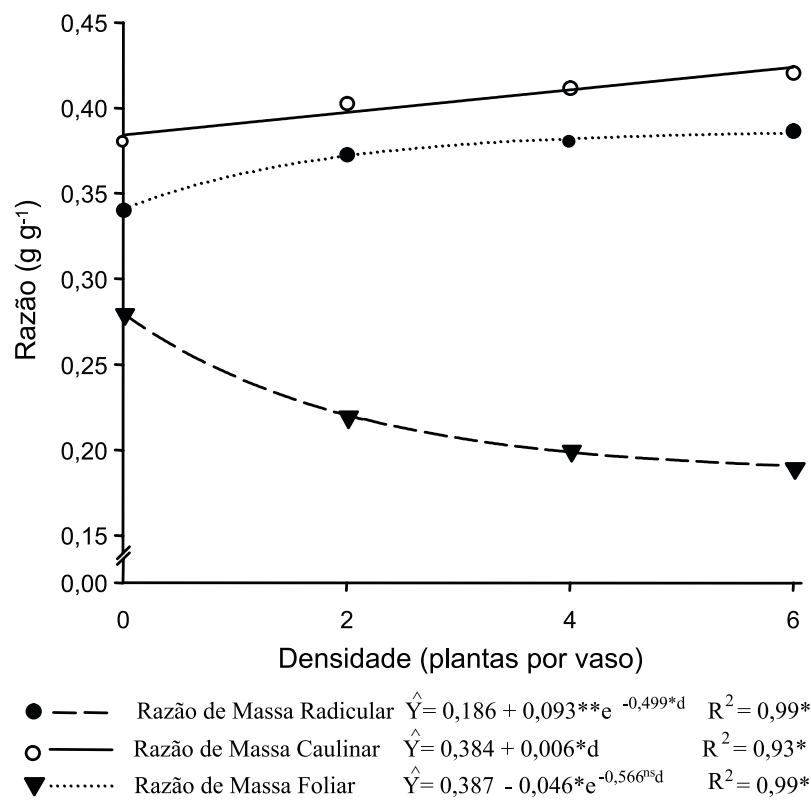

Figura 4 - Razão de massa radicular, razão de massa caulinar e razão de massa foliar de plantas de café em função da densidade de plantas daninhas, após 90 dias de convivência. (*,** Teste $\mathrm{F} ; \mathrm{P}<0,05$ e $\mathrm{P}<0,01$, respectivamente). maior razão de massa caulinar e maior razão de massa foliar. A competição propiciou diminuição da razão de massa radicular, ou seja, menos fotoassimilados foram alocados para o sistema radicular do café.

Em experimentos de curta duração, com suprimento homogêneo de recursos, as plantas alocam maior proporção de fotoassimilados para os órgãos responsáveis pela aquisição de recursos que estão limitados no ambiente (Shipley \& Meziane, 2002). Por outro lado, em condições de campo e por período de tempo mais longo, a disponibilidade de recursos do ambiente costuma ser temporalmente heterogênea, não se verificando alocação diferenciada de carboidratos entre raízes e parte aérea das plantas (Cahill Jr., 2003). A competição por recursos do solo e radiação solar não é independente, e tanto o sistema radicular como a parte aérea das plantas efetuam trocas rápidas no que se refere à alocação de fotoassimilados, quando uma ou outra fração é mais exigida para enfrentar a competição (Cahill Jr., 2002).

As alterações morfológicas observadas levaram a menor razão sistema radicular/ parte aérea do café, com o aumento da densidade de plantas daninhas (Figura 5). A partir dessa razão, pode-se inferir que houve menor alocação de fotoassimilados para o sistema radicular em relação à parte área das plantas de café em competição com as plantas daninhas.

Segundo Bianco et al. (2005), a $B$. decumbens é espécie muito exigente em termos nutricionais comparado a outras gramineas. Dessa forma, dependendo da fase de desenvolvimento da planta e da intensidade da competição, pode ocorrer alternância na importância relativa da competição por recursos abaixo e acima da superficie do solo. Contudo, a competição que ocorre nas fases iniciais de desenvolvimento por recursos do solo (Semere \& Froud-Williams, 2001) e a modulação do crescimento devido à qualidade de radiação solar (Ballaré \& Casal, 2000; Almeida \& Mundstock, 2001) definem o padrão de crescimento futuro de uma planta em relação aos seus vizinhos.

As plantas daninhas, desenvolvendo-se juntamente com o café, proporcionaram 


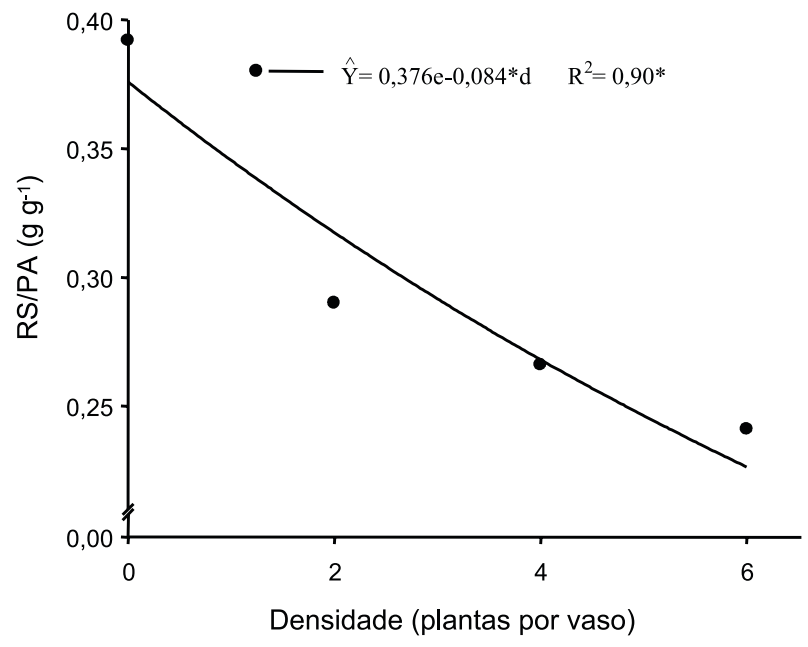

Figura 5 - Razão sistema radicular/parte aérea de plantas de café em função da densidade de plantas daninhas, após 90 dias de convivência. (* Teste $\mathrm{F}$; $\mathrm{P}<0,05$ )

interação negativa para ambas as espécies, havendo menor acúmulo do incremento de altura, área foliar e matéria seca total das plantas de café, principalmente à medida que se aumentou a densidade das plantas daninhas. As plantas de café mais jovens (60 DAT) parecem ser mais sensiveis à interferência das plantas daninhas, pois houve menor acúmulo das variáveis de crescimento, principalmente com a máxima densidade de plantas, sendo que as duas gramineas comportaramse de forma similar não diferindo para a maioria das variáveis.

Para as plantas de café que passaram a conviver com as espécies de plantas daninhas aos 180 DAT, houve maior sensibilidade à competição com a B. plantaginea. Este fato pode estar relacionado ao acúmulo similar de matéria seca da $B$. plantaginea independentemente da época de desenvolvimento do café, enquanto a $B$. decumbens acumulou quase a metade da matéria seca quando desenvolveu com mudas maiores de café. A maior estatura da planta de café pode ter propiciado vantagem competitiva pelo recurso luz, possibilitando sombrear a espécie daninha, principalmente por ser espécie exigente neste recurso. A $B$. decumbens desenvolvendo juntamente com o café, aos 180 DAT, foi menos competitiva que a $B$. plantaginea, que apresentou desenvolvimento similar para o fator época de desenvolvimento do café (60 DAT e 180 DAT).
O aumento da densidade de plantas daninhas promoveu maior alocação para parte área em detrimento ao sistema radicular do café.

\section{LITERATURA CITADA}

ANTUNES, W. C. et al. Allometric models for nondestructive leaf area estimation in coffee (Coffea arabica and Coffea canephora). Ann. Appl. Biol., v. 59, n. 1, p. 1-8, 2008.

ALMEIDA, M. L.; MUNDSTOCK, C. M. A qualidade da luz afeta $\mathrm{o}$ afilhamento em plantas de trigo quando cultivadas sob competição. Ci. Rural, v. 31, n. 3, p. 40-408, 2001.

BALLARÉ, C. L.; CASAL, J. J. Light signals perceived by crop and weed plants. Field Crops Res., v. 67, n. 2, p. $149-160,2000$.

BIANCO, S.; TONHÃO, M. A. R.; PITELLI, R.A Crescimento e nutrição mineral de capim-braquiária Planta Daninha, v. 23, n. 3, p. 423-428, 2005.

CAHILL Jr., J. F. Interactions between root and shoot competition vary among species. Oikos, v. 99, n. 1, p. 101-112, 2002.

CAHILL Jr., J. F. Lack of relationship between below-ground competition and allocation to roots in 10 grassland species. J. Appl. Ecol., v. 91, n. 4, p. 532-540, 2003

CAIXETA, G. Z. T. et al. Gerenciamento como forma de garantir a competitividade da cafeicultura. Inf. Agropec. v. 29, n. 247 , p. $14-23,2008$

CRAINE, J. M. Competition for nutrients and optimal root allocation. Plant Soil, v. 285, n. 2, p. 171-185, 2006

DUNBADIN, V. Simulating the role of rooting traits in cropweed competition. Field Crop. Res., v. 104, n. 1, p. 44-51, 2007.

MARCOLINI, L. W. et al. Effect of the density and of the distance of Brachiaria decumbens staff on the initial growth of Coffea arabica seedlings. Coffee Sci., v. 4, n. 1, p. 11-15, 2009.

McCULLY, M. E. Roots in soil: unearthing the complexities of roots and their rhizospheres. Rev. Plant., v. 50, p. $695-718,1999$.

NJOROGE, J. M. Weeds and weed control in coffee. Exper. Agric., v. 30, n. 4, p. 421-429, 1994.

POORTER, H.; NAGEL, O. The role of biomass allocation in the growth response of plants to different levels of light, $\mathrm{CO}_{2}$ nutrients and water: a quantitative review. Austr. J. Plant.

Physiol., v. 27, n. 6, p. 595-607, 2000 
RONCHI, C. P. et al. Acúmulo de nutrientes pelo cafeeiro sob interferência de plantas daninhas. Planta Daninha, v. 21, n. 2, p. 219-227, 2003.

RONCHI, C. P.; SILVA, A. A. Effects of weed species competition on the growth of young coffee plants. Planta Daninha, v. 24, n. 2, p. 415-423, 2006.

SEMERE, T.; FROUD-WILLIAMS, R. J. The effect of pea cultivar and water stress on root and shoot competition between vegetative plants of maize and pea. J. Appl. Ecol., v. 38, n. 1, p. $137-145,2001$
SHIPLEY, B.; MEZIANE, D. The balanced-growth hypothesis and the allometry of leaf and root biomass allocation. Funct. Ecol., v. 16, n. 3, p. 326-331, 2002.

SILVA, A. A. et al. Manejo integrado de plantas daninhas em lavouras de café. In: TOMAZ, M. A. et al. (Eds.) SEMINÁRIO PARA A SUSTENTABILIDADE DA CAFEICULTURA. Alegre: UFES, 2008. p. 251-268.

SILVA, A. C. et al. Análise de crescimento de Brachiaria brizantha submetida a doses reduzidas de fluazifop-p-butil. Planta Daninha, v. 23, n. 1, p. 85-91, 2005. 